\title{
Rodda JC, Robinson M (eds) | Progress in modern hydrology: past, present and future
}

\author{
Richard Hooper ${ }^{1}$
}

(C) Springer-Verlag Berlin Heidelberg 2016

\section{5 | Wiley-Blackwell | 408 pp | Hardcover: ISBN 978-1-119-07427-4 | USD \$149.95, E-Book \$119.99}

This collection of papers was assembled to highlight the contributions of the Institute of Hydrology (IH), now the Center for Ecology and Hydrology (CEH). Along with an introductory chapter on their history of IH and a concluding chapter looking to the future, its ten central chapters on the scientific contributions are wide ranging. They consist of chapters on basin instrumentation (focusing on Plynlimon catchment), flood risk estimation, terrestrial hydrologic processes, land-surface interaction, water resources security, hydrologic modeling, water quality, ecohydrology, climate change impacts on hydrology and hydrologic data acquisition. This potpourri of topics reflects the wide range of study areas undertaken at $\mathrm{IH}$.

The chapters vary widely in comprehensiveness, but tend to focus on the contributions of IH scientists. Few of the chapters could be considered comprehensive topical reviews; rather, the contribution of these chapters is, in part, a historical review of the development of these topics and, in part, on social aspects of how hydrology is donethat it is a human endeavor that underlies the science as much as a review of the findings. Read in that light, this is an interesting volume for young scientists who tend not to appreciate either of these aspects of the scientific undertaking.

Richard Hooper

RHooper@cuahsi.org

1 Consortium of Universities for the Advancement of Hydrologic Science, Inc., 196 Boston Ave, Suite 3000, Medford, MA 02155, USA
More broadly, this volume celebrates the government funded research institution which has changed markedly over the 50 years covered by this volume. IH had and CEH has parallels in many other Western European countries and the USA. All of these institutes have faced radical changes in their funding models over the past 50 years, and various external pressures to undertake more interdisciplinary research (as evidenced by the name change) but also to be more accountable in a shorter time horizon. The latter has tended to focus a greater portion of the research portfolio on applied studies. Chapter 1 reviews the upheavals at IH in the light of reorganization and realignment. This history is worth recording and we all benefit from reflecting upon it. Have the reorganizations resulted in the intended outcomes?

The final chapter outlines future prospects. Its message is decidedly not unalloyed optimism. Greater progress has been made in some areas, such as interdisciplinary studies, yet some fundamentals (such as rigorous model testing) seem to have been lost. The central role of water in the economy and in the environment remains the raison d'etre for institutions such as CEH. The volume provides a basis to evaluate how well we have met that challenge in the past and allows us to ponder how to organize research to meet it in the future. 